\title{
A CRIAÇÃO DO VÍNCULO SOCIOAFETIVO COM O RECÉM- NASCIDO: AS DISPARIDADES ENTRE AS LICENÇAS OFERECIDAS AOS PAIS E A IMPORTÂNCIA DOS LAÇOS AFETIVOS
}

THE CREATION OF THE SOCIOAFFECTIVE BIND WITH THE NEWBORN: THE DISPARITIES BETWEEN LICENSES OFFERED TO PARENTS AND THE IMPORTANCE OF AFFECTIVE TIES

Felipe Queiroz TORRES ${ }^{1}$

ISSUE DOI: 10.21207/2675-0104.2019.793

\begin{abstract}
RESUMO
O objetivo geral do presente trabalho é enaltecer a proteção à maternidade, ao analisar os institutos da licença-maternidade e paternidade, salientando a importância dos laços afetivos na vida do recémnascido. O problema resumiu-se em apresentar a insuficiência dos institutos previstos na Constituição Federal, dando ênfase na disparidade dos prazos garantidos aos pais, o que acarreta no acúmulo dos cuidados da criança em somente um dos pais. O presente trabalho propõe-se a demonstrar a importância do afeto nas relações familiares, enfatizando a necessidade da presença de ambos os pais no início da vida de uma criança, sendo que para estabelecer vínculo afetivo familiar, é necessário a disposição de tempo, suprindo as necessidades físicas, mentais e emocionais do bebê. Faz-se uma análise do afeto e do desenvolvimento infantil na Psicanálise, tornando clara a importância do afeto no começo da vida de uma criança, sendo que a sua falta prejudica diretamente o desenvolvimento mental e emocional do recém-nascido. A proteção à maternidade deve ser sempre valorizada, sendo assim, amparado pelo Direito do Trabalho e pelo Direito de Família, faz-se necessário enaltecer os princípios da dignidade da pessoa humana e da afetividade, que valorizam à maternidade e a entidade familiar, garantindo ao recém-nascimento um tratamento justo e destacando a importância do afeto.
\end{abstract}

Palavras chave: Licença-maternidade. Licença-paternidade. Direito do Trabalho. Direito de Família. Afeto.

\footnotetext{
${ }^{1}$ Discente da Faculdade de Direito de Franca (FDF), Franca/SP. Bolsista do Programa Interno de Iniciação Cientítica (PIBIC 2017-2018).
} 


\begin{abstract}
The general objective of this study is to highlight maternity protection by analyzing the maternity leave and paternity institutes, emphasizing the importance of affective bonds in the life of the newborn. The problem was summarized in the insufficiency of the institutes provided for in the Federal Constitution, emphasizing the disparity of the periods guaranteed to parents, which entails the accumulation of child care in only one of the parents. This paper aims to demonstrate the importance of affection in family relationships, emphasizing the need for the presence of both parents at the beginning of the life of a child, and to establish a family affective bond, it is necessary to dispose of time, to supply the physical, mental and emotional needs of the baby. An analysis of affection and child development in psychoanalysis is made, making clear the importance of affection at the beginning of a child's life, and its lack directly impairs the mental and emotional development of the newborn. The protection of maternity should always be valued, and thus, supported by labor rights and family rights, it is necessary to extol the principles of human dignity and affection, which value maternity and the family entity, guaranteeing the newly born a fair treatment and highlighting the importance of affection.
\end{abstract}

Keywords: Maternity leave. Paternity leave. Labor rights. Family rights. Affection.

\title{
INTRODUÇÃO
}

A escolha do presente tema justifica-se pela valorização da proteção à maternidade, enaltecendo a necessidade dos cuidados com o recém-nascido, para garantir à criança a manutenção da vida e o desenvolvimento físico, mental e emocional saudável. Deve-se também ao pouco prazo de licença garantido aos pais, sendo que tornasse mais complexa a criação de vínculo afetivo entre pais e filhos, gerando prejuízos a entidade familiar. É devido ressaltar a importância desses laços afetivos na vida do recém-nascido, tendo em vista, que é de suma importância a presença dos pais para a formação de vínculo parental,

Tem a presente pesquisa a finalidade de identificar e mostrar a necessidade da criação de vínculo afetivo no meio familiar desde o nascimento. Foram analisados os institutos da licença maternidade e paternidade, enfatizando o seu conceito e aplicação no Direito brasileiro. Sendo apresentado os conceitos doutrinários referente à licença, ilustrando a função dos institutos, o prazo legal garantido aos pais e direitos inerentes à licença.

A importância dos laços afetivos, amparado no Direito de Família e na Psicanálise. Os artigos 226 e 229 da Constituição Federal de 1988, conceituam o valor contido na família e sua função na vida do recémnascido, foi apresentado os institutos da filiação e filiação socioafetiva e, alguns princípios do Direito de Família como a Dignidade da Pessoa Humana que é uma das maiores conquistas da sociedade contemporânea. 
A Psicanálise foi de grande valia para a presente pesquisa, com o uso da interdisciplinaridade, foi possível aprofundar no conceito de afeto e desenvolvimento infantil. $\mathrm{O}$ autor John Bowlby ilustra em seu livro a necessidade do afeto e carinho na vida do recém-nascido, enaltecendo que para um desenvolvimento físico, mental e emocional da criança, é preciso garantir a afetividade desde o nascimento.

\title{
2.1 O CONCEITO DE LICENÇA MATERNIDADE E PATERNIDADE
}

A palavra licença tem origem no Latim (Licentia), que significa o ato de dar permissão para alguém, tem o sentido de autorização concedida para executar determinada atividade. O autor Washington dos Santos conceitua licença em seu dicionário jurídico como:

\begin{abstract}
Licença - (Lat. licentia.) S.f. Consentimento, autorização, permissão; ato de consentir, pelo qual se autoriza ou se dá a faculdade de fazer determinada coisa; afastamento do serviço público por determinado tempo; afastamento do trabalho para tratamento de saúde, com laudo médico, ou para desempenho de mandato classista, à gestante, adotante ou licença paternidade ou para afazeres particulares, se assim o permitir a legislação a respeito. ${ }^{2}$
\end{abstract}

Para o Direito a palavra licença tem grande valia, sendo conceituada pelo Direito Administrativo como uma permissão do Poder Público para uma pessoa executar alguma atividade, após preencher os requisitos necessários. O autor Hely Lopes Meirelles esclarece que:

Licença - Licença é o ato administrativo vinculado e definitivo pelo qual o Poder Público, verificando que o interessado atendeu a todas as exigências legais, faculta-lhe o desempenho de atividades ou a realização de fatos materiais antes vedados ao particular, como, p.

\footnotetext{
${ }^{2}$ SANTOS, Washington dos. Dicionário Jurídico Brasileiro. Belo Horizonte: Del Rey, 2001. p. 151.
} 
ex., o exercício de uma profissão, a construção de um edifício em terreno próprio. ${ }^{3}$

A licença maternidade é um Direito Fundamental, presente no ordenamento jurídico brasileiro, com a finalidade de proteção à maternidade, à gestante e ao recém-nascido. Esse instituto é de suma importância na sociedade, pois é por meio deste que é garantido a manutenção da vida do recém-nascido, a criação do vínculo afetivo parental e a recuperação da mulher após o período de gestação, sem causar qualquer prejuízo a empregada no gozo do benefício. ${ }^{4}$

Implementada no Brasil na Constituição Federal de 1988, a licença paternidade é um instituto que foi criado na tentativa de aumentar a responsabilidade paterna nos cuidados com o recém-nascido, estimular a criação de laços afetivos entre pai e filho e proporcionar auxílio à mãe no período pós-gestação. A autora Alice Monteiro de Barros esclarece que " A licença maternidade foi alongada de 84 para 120 dias, e introduziu-se a licença paternidade de 5 dias. O objetivo do legislador foi tornar o pai cada vez mais responsável pelos cuidados com o filho e a companheira". 5

\subsection{PREVISÃO LEGAL DA LICENÇA MATERNIDADE E PATERNIDADE NO DIREITO BRASILEIRO}

As doutrinas de Direito do Trabalho abordam a licençamaternidade e paternidade no capítulo de interrupção e suspensão do contrato de trabalho. A interrupção do pacto laboral é conceituada como uma das possibilidades prevista na CLT de paralisação contratual, com a finalidade de sustar provisoriamente durante um lapso de tempo a prestação de trabalho e disponibilidade do empregado com o empregador, tendo em vista que é mantido o vínculo empregatício entre as partes, sendo garantido ao empregado a manutenção do salário de forma integral e o cômputo do tempo deste afastamento para todos os efeitos legais provenientes do pacto laboral. Sendo assim, a sustação dos efeitos do contrato é unilateral. ${ }^{6}$ A Suspensão é a paralização do contrato de trabalho,

\footnotetext{
${ }^{3}$ MIRELLES, Hely Lopes. Direito Administrativo Brasileiro. 23. ed. São Paulo: Malheiros, 1998. p.161.

${ }^{4}$ BARROS, A. M. Curso de direito do trabalho. 10. ed. São Paulo: LTr, 2016, p. 59 -61 e 710-713.

${ }^{5}$ BARROS, A. M. Curso de direito do trabalho. 10. ed. São Paulo: LTr, 2016, p.61.

${ }^{6}$ DELGADO, Mauricio Godinho. Curso de Direito do Trabalho. 16. ed. São Paulo: LTr, 2017, p.1207.
} 
que também susta a prestação de trabalho e disponibilidade entre as partes e mantém o vínculo empregatício, contudo, na suspensão de contrato também é paralisado a contraprestação do empregador e o cômputo do tempo dessa suspensão para fins legais. Desta forma, a sustação dos efeitos do contrato é bilateral. ${ }^{7} \mathrm{O}$ autor Amauri Mascaro Nascimento esclarece:

Nossa lei se utiliza de dupla terminologia, suspensão e interrupção, a nosso ver sem caráter substancial porque diz respeito única mente aos efeitos e não ao conceito. A figura tem um pressuposto comum, paralisação do trabalho, sendo diferentes os efeitos que a paralisação produzirá, especialmente quanto aos salários; haverá interrupção quando devidos os salários, e suspensão quando não devidos. Essa é a linguagem do nosso direito, mas outra poderia ser sem alteração básica, chamando-se de suspensão remunerada ou não remunerada as duas hipóteses, ou suspensão parcial ou total, como fazem alguns doutrinadores. ${ }^{8}$

Em relação à classificação da licença-maternidade, a doutrina não estabelece uma unanimidade, sendo que alguns doutrinadores classificam esse instituto como interrupção do contrato de trabalho e outros o definem como suspensão. O autor Maurício Godinho Delgado faz a seguinte classificação:

\begin{abstract}
A maioria da doutrina, entretanto, insiste que o correto enquadramento, no presente caso, é o que se reporta à interrupção contratual. E com inteira razão, sem dúvida. De fato, todos os efeitos básicos da interrupção comparecem à presente situação trabalhista. Ilustrativamente, mantém-se a plena contagem do tempo de serviço obreiro para todos os fins; mantém-se o direito às parcelas que não sejam salário condição; mesmo quanto a estas, se forem habituais, mantém-se a obrigação de seu reflexo no cálculo do montante pago à obreira no período de afastamento; preservase, por fim, a obrigação empresarial de realizar depósitos de FGTS na conta vinculada da empregada no período de licença. ${ }^{9}$
\end{abstract}

Em contrapartida, a autora Alice Monteiro de Barros faz uma diferente análise sobre o mesmo instituto:

À luz da Constituição, a empregada no ciclo gravídico-puerperal faz jus à licença-maternidade de 120 dias, devendo afastar-se entre o $28^{\circ}$ dia antes do parto e a ocorrência deste. A licença é compulsória e órgão previdenciário arcará com o pagamento do

\footnotetext{
${ }^{7}$ BARROS, A. M. Curso de direito do trabalho. 10. ed. São Paulo: LTr, 2016, p.568.

${ }^{8}$ NASCIMENTO, A. M. Curso de direito do trabalho: história e teoria geral do direito do trabalho: relações individuais e coletivas do trabalho. 26. ed. São Paulo: Saraiva, 2011, p.1121.

${ }^{9}$ DELGADO, Mauricio Godinho. Curso de Direito do Trabalho. 16. ed. São Paulo: LTr, 2017, p.1226.
} 
salário-maternidade. Em casos excepcionais os períodos de licença antes e depois do parto poderão ser aumentados de duas semanas, mediante atestado médico fornecido pelo SUS. Assegura-se a licença de 120 dias na hipótese de parto antecipado e duas semanas em caso de aborto não criminoso. Situamos essas hipóteses como de suspensão do contrato de trabalho, porque não há salário. A contribuição, conforme salientado, é pago pelo órgão previdenciário. ${ }^{10}$

De acordo com o artigo 473, alínea c, da Consolidação das Leis do Trabalho, a licença-paternidade é enquadrada como interrupção do contrato de trabalho, pois diferentemente da licença-maternidade o benefício é pago integralmente pelo empregador, sendo sustado somente a prestação de serviços do empregado.

A licença-maternidade e a licença-paternidade estão previstas no artigo $7^{\circ}$ da Constituição Federal de 1988, onde são garantidos 120 dias de licença à mãe, expresso no inciso XVIII. O inciso XIX estabelece que a licença-paternidade será fixada por lei, por isso foi instituído no Ato das Disposições Constitucionais Transitórias (ADCT) em seu artigo $10 \S 1^{\circ}, 5$ dias de licença, até que se crie lei complementar para regulamentar este prazo.

É valido ressaltar que além dos prazos previsto na Constituição Federal e no ADCT, existe a possibilidade de ampliação da duração da licença por meio do programa Empresa Cidadã, onde a licença maternidade é aumentada de 120 para 180 dias, e a paternidade de 5 para 20 dias. $^{11}$ Contudo, o programa será abordado neste trabalho em capítulo posterior.

Após quase trinta anos de vigência da Constituição atual, a lei que regulamenta a licença-paternidade ainda não foi criada, tendo em vista que essa medida foi prevista no ADCT, faz-se necessário citar o conceito de inconstitucionalidade por omissão, descrito pelo autor Luiz Guilherme Marinoni:

Determinadas normas constitucionais impõem ao legislador o dever de regulamentá-las. Valem-se de expressões como "conforme definido em lei" para evidenciar que necessitam de complementação infraconstitucional. Tanto as normas constitucionais ditas de "organização" - como a do art. 178, que afirma que a "lei disporá sobre a ordenação dos transportes aéreo, aquático e terrestre" —, quanto as normas que propriamente definem direitos - como a do art. $7 .^{\circ}, \mathrm{IX}$, que diz que "são direitos dos trabalhadores, além de outros, participação nos lucros ou

\footnotetext{
${ }^{10}$ BARROS, A. M. Curso de direito do trabalho. 10. ed. São Paulo: LTr, 2016, p.573.

${ }^{11}$ DELGADO, Mauricio Godinho. Curso de Direito do Trabalho. 16. ed. São Paulo: LTr, 2017, p.1224.
} 
resultados, conforme definido em lei" - , dão origem a casos de omissão inconstitucional diante da inação do legislador. ${ }^{12}$

A omissão por parte do legislador na criação da lei que regulamente o instituto da licença-paternidade, prejudica diretamente a entidade familiar, desamparando e atingindo diretamente a família por aproximadamente três décadas, o que gera um impacto direto na criação de vínculo afetivo entre pais e filhos e colabora para o acúmulo da responsabilidade dos cuidados do recém-nascido serem direcionados à mãe.

\section{A IMPORTÂNCIA DOS LAÇOS AFETIVOS}

\subsection{CONCEITO DE AFETO NO DIREITO DE FAMÍLIA}

Conceituado no Direito de Família, o afeto é a base das relações sociais de um indivíduo. A doutrina traz o conceito de afeto por meio do princípio da afetividade, que versa que o afeto é o principal elemento na criação de vínculo entre duas pessoas, o liame socioafetivo que cria o vínculo presente entre pais e filhos. ${ }^{13} \mathrm{O}$ autor Flávio Tartuce aborda o princípio da afetividade, que ressalta a importância do afeto:

$\mathrm{O}$ afeto talvez seja apontado, atualmente como o princípio fundamental das relações familiares. Mesmo não constando a expressão afeto no Texto Maior como sendo um direito fundamental, pode-se afirmar que ele decorre da valorização constante da dignidade humana. Por isso é que, para fins didático e metodológicos destaca-se o princípio em questão [...]. ${ }^{14}$

O princípio da afetividade está relacionado com os conceitos de filiação e filiação afetiva, sendo a filiação o vínculo jurídico criado entre ascendentes e descente de primeiro grau por meio de um parentesco de consanguinidade, ou seja, o liame biológico criado entre pais e filhos. ${ }^{15} \mathrm{~A}$

\footnotetext{
${ }^{12}$ SARLET, Ingo Wolfgang; MARINONI, Luiz Guilherme; MITIDIERO, Daniel. Curso de Direito Constitucional. São Paulo: Revistas dos Tribunais, 2012. p.788.

${ }^{13}$ GAGLAINO, Pablo Stolze; PAMPLONA FILHO, Rodolfo. Novo curso de direito civil: Direito de família. 4. ed. São Paulo: Saraiva, 2014. 6 v, p. 89-94.

${ }^{14}$ TARTUCE, Flávio. Direito civil: direito de família. 9. ed. Rio de Janeiro: Forense, 2014. 5 v, p. 24.

${ }^{15}$ TARTUCE, Flávio. Direito civil: direito de família. 9. ed. Rio de Janeiro: Forense, 2014. 5 v, p. 262.
} 
filiação afetiva enaltece a presença do amor nas relações parentais, concluindo que a afetividade se sobrepõe sobre o vínculo biológico. A autora Jacqueline Filgueras Nogueira esclarece a filiação afetiva:

\begin{abstract}
Para a criança, sua simples origem fisiológica não leva a ter vínculo com seus pais; a figura dos pais, para ela, são aqueles com quem ela tem relações de sentimento, aqueles que se entregam ao seu bem, satisfazendo suas necessidades de carinho, alimentação, cuidado e atenção. Pode-se dizer que existem dois momentos referentes à filiação: um fisiológico, que determina a filiação biológica, e um psicológico, que determina a filiação afetiva, sendo esta decorrente da criança se sentir segura e desejada. Os próprios pais -biológicos podem ser os que atendam às necessidades psicológicas, mas, quando estes são ausentes e não estabelecem vínculo com a criança, são para os sentimentos dela, simplesmente estranhos. ${ }^{16}$
\end{abstract}

O princípio em questão, não busca conceituar o amor, contudo, enaltece que o amor é um fator necessário na criação de afeto entre duas pessoas, como observado na adoção de uma criança por uma família, sendo que neste caso, não existe qualquer vínculo biológico, sendo este, fundando na afetividade que é criada por meio da disposição dos adotantes perante ao adotado, satisfazendo suas necessidades de carinho, alimentação e cuidados.

\title{
3.2 CONCEITO DE FAMÍLIA
}

A importância da família para o recém-nascido é sem dúvida imensurável, a necessidade do amparo dos pais, para a manutenção da vida da criança e a criação de vínculo afetivo desde os primeiros dias de vida, demonstra a necessidade da presença dos pais na vida de um recémnascido. A Constituição Federal de 1988 em seu artigo 226, enaltece o valor contido na família e a considera como base da sociedade. As doutrinas de Direito de família se preocupam em não enfatizar um só conceito de família, pois devido a evolução social, esse conceito sofreu transformações. A autora Maria Berenice Dias demonstra a complexidade deste conceito:

Difícil encontrar uma definição de família de forma a dimensionar o que, no contexto social dos dias de hoje, se insere nesse conceito.

\footnotetext{
${ }^{16}$ NOGUEIRA, Jacqueline Filgueras. A filiação que se constrói: o reconhecimento do afeto como
} valor jurídico. São Paulo: Memória Jurídica, 2001, p.86. 
É mais ou menos intuitivo identificar a família com a noção de casamento, ou seja, pessoas ligadas pelo vínculo do matrimônio. Também vem à mente a imagem da família patriarcal, o pai como a figura central, tendo ao lado a esposa, rodeados de filhos, genros, noras e netos. Essa visão hierarquizada da família, no entanto sofreu, com o tempo, enormes transformações. Além da significativa diminuição do número de seus componentes, também começou a haver um embaralhamento de papéis. A emancipação feminina e o ingresso da mulher no mercado de trabalho levaramna para fora do lar. Deixou o homem de ser o provedor exclusivo da família, e foi exigida sua participação nas atividades domésticas. ${ }^{17}$

O novo conceito de família é fundado na afetividade, na pluralidade e no eudemonismo, sendo assim, é preciso uma visão pluralista da família, para desta forma, considerar como entidade familiar qualquer tipo de relacionamento que ocorra um vínculo afetivo, independentemente da sua formação. A união homoafetiva é o exemplo que ilustra a evolução do conceito de família, que antigamente influenciada pelo preconceito e proximidade do Estado com a igreja, não considerava com status de família a união de pessoas do mesmo sexo. ${ }^{18}$

\subsection{PRINCÍPIOS APLICÁVEIS AO DIREITO DE FAMÍLIA}

No tocante a afetividade e a entidade familiar, alguns princípios aplicáveis ao Direito de Família são de grande valia para o recém-nascido. Uma das maiores conquistas do Direito brasileiro nos últimos anos, o princípio da dignidade da pessoa humana garante o direito de se viver plenamente, assegura a todos uma vida digna e de respeito à existência humana. Sendo assim, é garantido ao recém-nascido a proteção à maternidade e o convívio familiar. O Autor Pablo Stolze Gagliano versa que:

Princípio solar em nosso ordenamento, a sua definição é missão das mais árduas, muito embora arrisquemo-nos a dizer que a noção jurídica de dignidade traduz um valor fundamental de respeito à existência humana, segundo as suas possibilidades e expectativas,

\footnotetext{
${ }^{17}$ DIAS, Maria Berenice. Manual de direito das famílias. 9. ed. São Paulo: Revistas dos Tribunais, 2014, p. 41.

${ }^{18}$ DIAS, Maria Berenice. Manual de direito das famílias. 9. ed. São Paulo: Revistas dos Tribunais, 2014, p. 41-47.
} 
patrimoniais e afetivas, indispensáveis à sua realização pessoa e à busca da felicidade. ${ }^{19}$

O artigo 229 da Constituição Federal de 1988 versa que "Os pais têm o dever de assistir, criar e educar os filhos menores, e os filhos maiores têm o dever de ajudar e amparar os pais na velhice, carência ou enfermidade.". O artigo em questão é a base do princípio da solidariedade que tem origem nos laços afetivos e dispõe que nas relações familiares, a solidariedade deve estar presente entre os membros da família, ocorrendo a fraternidade e solidariedade. A importância desse princípio para o recémnascido se explica no dever de assistência dos pais perante a criança, para desta forma, garantir de maneira saudável a manutenção da vida do recémnascido. $^{20}$

O princípio da convivência familiar é também significativo ao recém-nascido, pois é por meio deste que é garantido à criança o direito da convivência com aqueles que possuem vínculo afetivo, sendo assegurado a não separação de pais e filhos, enaltecendo que os mesmos devem permanecer juntos. Esse princípio garante que a criança mantenha os laços afetivos já estabelecidos, ampliando para pessoas diferentes dos pais, como avós, tios e irmãos o direito de convivência por meio da afetividade. ${ }^{21}$

\subsection{O CONCEITO DE AFETO NA PSICANÁLISE}

A interdisciplinaridade faz-se necessária nesta pesquisa, pois por meio desta que se torna possível aprofundar o conceito de afeto, que no Direito brasileiro, não é profundamente abordado, sendo exposto principalmente no princípio da afetividade e na filiação afetiva, já citados no item anterior. Sendo assim, amparado nas doutrinas da Psicanálise, com o intuito de expor com mais amplitude o afeto, a sua importância e os efeitos proporcionados na vida do recém-nascido.

Os dicionários de Psicanálise conceituam o afeto como uma pulsão, que exprime o estado afetivo, expressado por meio de uma descarga

\footnotetext{
${ }^{19}$ GAGLAINO, Pablo Stolze; PAMPLONA FILHO, Rodolfo. Novo curso de direito civil: Direito de família. 4. ed. São Paulo: Saraiva, 2014. 6 v, p. 76.

${ }^{20}$ DIAS, Maria Berenice. Manual de direito das famílias. 9. ed. São Paulo: Revistas dos Tribunais, 2014, p. 69.

${ }^{21}$ GAGLAINO, Pablo Stolze; PAMPLONA FILHO, Rodolfo. Novo curso de direito civil: Direito de família. 4. ed. São Paulo: Saraiva, 2014. 6 v, p. 104.
} 
maciça de energia pulsional. Contudo, para compreender o conceito de afeto exposto acima, é necessário a compreensão do significado de pulsão. ${ }^{22} \mathrm{O}$ dicionário de Psicanálise dos autores Elisabeth Roudinseco e Michel Plon expressa o conceito de pulsão:

Termo surgido na França em 1625, derivado do latim pulsio, para designar o ato de impulsionar. Empregado por Sigmund Freud a partir de 1905, tornou-se um grande conceito da doutrina psicanalítica, definido como a carga energética que se encontra na origem da atividade motora do organismo e do funcionamento psíquico inconsciente do homem. ${ }^{23}$

Com base nos conceitos da afetividade e pulsão contidos na psicanálise, o afeto é definido como a disposição energética investida por uma pessoa, para desta forma criar uma relação com outrem, ou seja, é todo o empenho, dedicação, carinho que é disposto nas relações pessoais para a criação e fortalecimento do vínculo entre pais e filhos. O Autor John Bowlby esclarece que:

O que se sabe hoje acerca da ontogenia dos vínculos afetivos sugere que estes se desenvolvem porque a criatura nasce com uma forte inclinação para se aproximar de certas classes de estímulos, notadamente os que lhe são familiares, e para evitar outras classes de estímulos - os estranhos. ${ }^{24}$

Ilustrado sabiamente pela Autora Jacqueline Filgueras Nogueira, a afetividade para a criança, supera inclusive a ligação biológica decorrente da filiação, sendo essa apenas o liame jurídico criado entre o genitor e sua prole, sendo que o vínculo afetivo só é obtido por meio da convivência familiar, suprimento das necessidades físicas e psicológicas da criança, garantindo o seu bem-estar. ${ }^{25}$

\subsection{A FORMAÇÃO DOS LAÇOS AFETIVOS}

Até a década de 1950, a formação dos vínculos afetivos era conceituada pelos psicanalistas e teóricos da aprendizagem como a busca do ser humano para satisfazer os seus impulsos infantis como a alimentação

\footnotetext{
${ }^{22}$ TAMEN, Pedro. Vocabulário da psicanálise. 7. ed. São Paulo: Martins Fontes, 1983, p. 34-36.

${ }^{23}$ ROUDINSECO, Elisabeth; PLON, Michel. Dicionário de psicanálise. Rio de Janeiro: Zahar, 1998, p. 628.

${ }^{24}$ BOWLBY, John. Formação e rompimento dos laços afetivos. 2. ed. São Paulo: Martins Fontes, 1990 , p. 66.

${ }^{25}$ NOGUEIRA, Jacqueline Filgueras. A filiação que se constrói: o reconhecimento do afeto como valor jurídico. São Paulo: Memória Jurídica, 2001, p.86-89.
} 
e a busca pelo afeto, e os impulsos da vida adulta como o estabelecimento de uma relação sexual com outro indivíduo, sendo assim, uma pessoa procurava no outro a forma de sanar seus impulsos. Os impulsos eram classificados como primários e secundários, sendo primário a busca pelo sexo e alimentação, e secundário as relações pessoais estabelecidas. ${ }^{26}$

A teoria da ligação que perdura até os dias atuais, modifica a teoria anterior e define a formação dos laços afetivos como a propensão dos seres humanos para a criação de fortes vínculos com demais indivíduos, e atrela problemas psicológicos exteriorizados na vida adulto à falta de afeto. O Autor John Bowlby conceitua de forma clara a teoria da ligação:

\begin{abstract}
Em suma, o comportamento de ligação é concebido como qualquer forma de comportamento que resulta em que uma pessoa alcance ou mantenha a proximidade com algum outro indivíduo diferenciado e preferido, o qual é usualmente considerado mais forte e ou mais sábio. Embora seja especialmente evidente durante os primeiros anos da infância, sustenta-se que o comportamento de ligação caracteriza os seres humanos do berço à sepultura. Inclui o choro e o chamamento, que suscitam cuidados e desvelos, o seguimento e o apego, e também os vigorosos protestos se uma criança ficar sozinha ou na companhia de estranhos. ${ }^{27}$
\end{abstract}

Bowlby descreve que os comportamentos relacionados à ligação não são um padrão para todos seres humanos, cada pessoa se comporta na questão da afetividade de acordo com as experiências obtidas no decorrer da vida, dando ênfase para aquelas obtidas nos primeiros anos de vida. Desta forma, expõe a características da teoria da ligação: A especificidade, a duração, o envolvimento emocional, a ontogenia, a aprendizagem, a organização e a função biológica. ${ }^{28}$

A especificidade é o comportamento de ligação que será direcionado para pessoas específicas, ou seja, a ligação é um ato pessoal, sendo determinado para um indivíduo certo, e expresso geralmente em ordem preferencial, dando ênfase para aquele que mais desperta a proximidade.

A duração é a ligação que perdura usualmente por toda a vida de uma pessoa, sendo que as ligações criadas na infância, dificilmente são

\footnotetext{
${ }^{26}$ BOWLBY, John. Formação e rompimento dos laços afetivos. 2. ed. São Paulo: Martins Fontes, 1990, p. 119-121.

${ }^{27}$ BOWLBY, John. Formação e rompimento dos laços afetivos. 2. ed. São Paulo: Martins Fontes, 1990, p. 122.

${ }^{28}$ BOWLBY, John. Formação e rompimento dos laços afetivos. 2. ed. São Paulo: Martins Fontes, 1990, p. 122-124.
} 
perdidas com o decorrer do tempo. Contudo, existe a possibilidade da substituição das ligações já criadas, por novas ligações.

O envolvimento emocional são as emoções dos seres humanos que refletem na criação dos vínculos afetivos. A criação do vínculo é explicada com o sentimento de paixão, ou seja, o estabelecimento desse vínculo passa pela fase de se apaixonar pelo outro. A manutenção do vínculo afetivo é descrita como a emoção de amar alguém, isto é, o vínculo já existe e permanece em virtude desse amor. O rompimento do laço afetivo, é conceituado no sentimento de perda de um companheiro, ou seja, a sensação de sofrer por alguém. Sendo assim, é notório que as emoções são o reflexo dos vínculos afetivos estabelecidos entre as pessoas.

A ontogenia explica que o comportamento de ligação é desenvolvido principalmente nos nove primeiros meses de vida, e versa que o vínculo afetivo de uma criança, será determinado em virtude das experiências obtidas com aquele que está suprindo suas necessidades físicas e psicológicas. Desta forma, será preferido pela criança o contato com a pessoa que dispôs maior tempo nos cuidados maternos, sendo essa a principal referência afetiva para a criança.

A aprendizagem é de suma importância para o desenvolvimento da criança, ela acontece na presença dos pais, sendo que os mesmos devem educar, ensinando desde bebê o que é certo e errado. O processo de aprendizagem proporciona um fortalecimento na ligação afetiva, pois por meio deste ocorre as experiências cotidianas da criança.

A organização refere-se ao comportamento de ligação que é expressado pela criança, ou seja, são os sistemas comportamentais que expressam por meio de modelos de representação, pelo ambiente de convivência e da decorrência da personalidade do bebê. Essas condições são ativadas por exemplo com a fome e o cansaço, sendo observado o comportamento da criança perante essas situações.

A função biológica da ligação é explicada pela necessidade de proteção, isto é, o recém-nascido é incapaz de satisfazer todas suas necessidades físicas e psicológicas, sendo assim, a ligação com os pais é também relacionada com questão biológica, pois em virtude do vínculo criado com pais ele pode sanar essas necessidades.

A teoria da ligação se diferencia do conceito de dependência, pois a este não está atrelado o conceito de afetividade, isto é, não existe na dependência a proximidade entre os indivíduos, existindo somente a relação vinculativa entre duas pessoas. É necessário ressaltar, que na 
dependência não são observadas as emoções já citadas na teoria da ligação, sendo assim, nenhuma função biológica lhe é atribuída. ${ }^{29}$

\subsection{ROMPIMENTOS DOS LAÇOS AFETIVOS}

A presença familiar é primordial na vida de uma criança, ter o convívio com os pais, a afetividade e a plena satisfação das necessidades físicas e emocionais, resultam no desenvolvimento saudável. De acordo com a teoria da ligação o bebê que cresce na companhia dos pais que proporcionam condições saudáveis se torna uma pessoa segura e autoconfiante. A autora Maria Luiza Dias esclarece:

A criança dependerá da mãe em quase tudo para sobreviver. Se não lhe derem alimento e não cuidarem dela, é provável que morra Não poderá fazer nada por si.

Também quanto a recursos psíquicos essas leis são semelhantes. A criança não vem ao mundo com repertório para se avaliar, avaliar a realidade externa e escolher comportamentos adequados. Isso tudo será garantido a partir da convivência familiar. ${ }^{30}$

John Bowlby faz uma análise sobre a necessidade de carinho entre pais e filho e discorre sobre os efeitos decorrentes dessa relação. $\mathrm{O}$ autor versa que:

Se um bebê tem o amor e a companhia de sua mãe e logo também de seu pai, ele crescerá sem uma pressão exagerada de anseios libidinais e sem uma propensão irresistível para odiar. Se não tiver essas coisas, seus anseios libidinais provavelmente serão muito elevados, o que significa, que o bebê está procurando constantemente amor e afeição, e será continuamente propenso a odiar aqueles que não conseguem - ou lhe parecem não conseguir - dar-lhe o afeto que ele tanto deseja. ${ }^{31}$

Contudo, muitas crianças crescem sem essa referência familiar, vivem uma realidade que os pais não proporcionam as condições necessárias para o desenvolvimento infantil de maneira plena. A descontinuidade da parentalidade é a interrupção do vínculo afetivo, ou o

\footnotetext{
${ }^{29}$ BOWLBY, John. Formação e rompimento dos laços afetivos. 2. ed. São Paulo: Martins Fontes, 1990, p. 124.

${ }^{30}$ DIAS, Maria Luiza. Vivendo em família: relações de afeto e conflito. São Paulo: Moderna, 1992, p. 6.

${ }^{31}$ BOWLBY, John. Formação e rompimento dos laços afetivos. 2. ed. São Paulo: Martins Fontes, 1990, p. 8.
} 
não estabelecimento desses laços. A teoria da ligação expressa que a falta da afetividade que está relacionada com a descontinuidade da parentalidade, o que pode causar danos ao desenvolvimento da criança, como a ligação ansiosa, que consiste em um comportamento extremamente ansioso, em virtude da falta de carinho e suprimento das necessidades físicas e psicológicas da criança. ${ }^{32}$

John Bowlby faz uma análise sobre o que a privação dos cuidados maternos pode resultar na vida de um recém-nascido:

\begin{abstract}
Dos muitos outros padrões de funcionamento familiar e desenvolvimento da personalidade perturbados que podem ser entendidos em termos do desenvolvimento patológico do comportamento de ligação, um dos mais conhecidos é o indivíduo emocionalmente desligado, incapaz de manter um vínculo afetivo estável com quem quer que seja. As pessoas com essa incapacidade são classificadas como psicopatas e (ou) histéricas. São frequentemente delinquentes e suicidas. A história típica é de prolongada privação de cuidados materno durante os primeiros anos de vida, geralmente combinada com rejeição posterior ou ameaças de rejeição pelos pais ou pais adotivos. ${ }^{33}$
\end{abstract}

Os vínculos afetivos obtidos na infância, tendem a permanecer inalterados na vida adulta, sendo que a forma de ligação criada na infância, ou seja, a maneira que foi estabelecido os vínculos afetivos, é mantida e tomada como base nas relações que serão criadas por esse indivíduo com pessoas distintas do seu meio familiar. Sendo assim, é necessário ressaltar a importância das primeiras experiências vivenciadas pelo recém-nascido, sendo que é extremamente necessário a convivência com ambos os pais, para garantir um desenvolvimento saudável durante a infância, para assegurar a manutenção da vida e estabelecer e fortalecer os laços afetivos com o bebê. A presença tanto do pai quanto da mãe é de suma importância, pois devido a teoria da ligação, a criança só cria vínculo com aquele que dispõe de tempo para satisfazer as suas necessidades. ${ }^{34}$

Desta forma, as licenças maternidade e paternidade já expostas na presente pesquisa, não condizem com as necessidades afetivas de um bebê. Os prazos de 120 dias da licença maternidade e 5 dias da licença paternidade, expõem uma incompatibilidade com o princípio da

\footnotetext{
${ }^{32}$ BOWLBY, John. Formação e rompimento dos laços afetivos. 2. ed. São Paulo: Martins Fontes, 1990, p. 128-130.

${ }^{33}$ BOWLBY, John. Formação e rompimento dos laços afetivos. 2. ed. São Paulo: Martins Fontes, 1990, p. 133.

${ }^{34}$ MUSIC, Granham. Afetos e emoções. Tradução: Carlos Mendes São Paulo: Segmento-duetto, 2005, p. 24-35.
} 
afetividade, o princípio da dignidade da pessoa humana e em claro desacordo com os artigos 226 e 229 da Constituição Federal, que versam e asseguraram a valorização e respeito da entidade familiar.

\section{CONSIDERAÇÕES FINAIS}

O valor dos laços afetivos para o recém-nascido, é sem dúvidas imensurável, a criança estabelece o vínculo parental, por meio da convivência com pais. É certo que a proteção da maternidade deve ser sempre valorizada, após a análise dos institutos da licença maternidade e paternidade torna-se evidente que as suas funções não se restringem somente à manutenção da vida do recém-nascido, como também, para a criação dos laços afetivos e o desenvolvimento físico, mental e emocional de forma saudável.

A omissão do Poder Legislativo na proteção à maternidade prejudica diretamente a entidade familiar. A não ampliação dos institutos colaboram para a concentração das obrigações de cuidados da criança em somente um dos pais, ou seja, devido a disparidade dos prazos garantidos, aquele que usufruiu de um prazo de licença maior tende a acumular as obrigações para garantir a manutenção da vida da criança. A disparidade de prazo nos institutos, também colaboram para diferenciar o vínculo afetivo com o recém-nascido, tendo em vista, que o representante familiar que dispor de maior tempo para satisfazer as necessidades físicas e emocionais do bebê, estabelecerá um liame afetivo mais sólido e duradouro, conforme exposto pela teoria da ligação contida na Psicanálise.

Desta forma, foi o objetivo principal demonstrar a importância dos laços afetivos para o recém-nascido, enaltecendo a necessidade da ampliação dos institutos da licença maternidade e paternidade. $\mathrm{O}$ afeto é o liame das relações sociais, sendo assim a sua valorização é garantida por meio da convivência entre pais e filhos. Com isso, é clara a insuficiência dos institutos no Direito Brasileiro, tornando injusta e desigual a obrigação referente ao recém-nascido, sendo que os prazos estabelecidos prejudicam a criança, que é o maior interessado no direito a licença. Sendo assim, devese ressaltar as possibilidades de ampliações dos institutos, enaltecendo os prazos garantidos na Suécia, que não só proporcionam tempo suficiente para o desenvolvimento saudável do bebê, como possibilitam uma adequação entre os responsáveis, para assim, satisfazer da melhor maneira as necessidades da criança no começo da vida. 


\section{REFERÊNCIAS BIBLIOGRÁFICAS}

BACHUR, Tiago Faggioni; BACHUR, Tânia Faggioni. Licença maternidade e salário maternidade na teoria e na prática. Franca: Lemos e Cruz, 2011.

BARROS, A. M. Curso de direito do trabalho. 10. ed. São Paulo: LTr, 2016

BOWLBY, John. Formação e rompimento dos laços afetivos. 2. ed. São Paulo: Martins Fontes, 1990.

CALIL, L. E. S. Direito do trabalho da mulher: questão da igualdade jurídica ante a desigualdade fática. São Paulo: LTr, 2007.

DELGADO, Mauricio Godinho. Curso de direito do trabalho. 16. ed. São Paulo: LTr, 2017.

DIAS, Maria Berenice. Manual de direito das famílias. 9. ed. São Paulo: Revistas dos Tribunais, 2014.

DIAS, Maria Luiza. Vivendo em família: relações de afeto e conflito. São Paulo: Moderna, 1992.

MIRELLES, Hely Lopes. Direito administrativo brasileiro. 23. ed. São Paulo: Malheiros, 1998.

MUSIC, Granham. Afetos e emoções. Tradução: Carlos Mendes São Paulo: Segmento-duetto, 2005.

NASCIMENTO, A. M. Curso de direito do trabalho: história e teoria geral do direito do trabalho: relações individuais e coletivas do trabalho. 26. ed. São Paulo: Saraiva, 2011.

NOGUEIRA, Jacqueline Filgueras. A filiação que se constrói: o reconhecimento do afeto como valor jurídico. São Paulo: Memória Jurídica, 2001.

ROUDINSECO, Elisabeth; PLON, Michel. Dicionário de psicanálise. Rio de Janeiro: Zahar, 1998.

SANTOS, Washington dos. Dicionário jurídico brasileiro. Belo Horizonte: Del Rey, 2001.

SARLET, Ingo Wolfgang; MARINONI, Luiz Guilherme; MITIDIERO, Daniel. Curso de direito constitucional. São Paulo: Revistas dos Tribunais, 2012.

TAMEN, Pedro. Vocabulário da psicanálise. 7. ed. São Paulo: Martins Fontes, 1983.

TARTUCE, Flávio. Direito civil: direito de família. 9. ed. Rio de Janeiro: Forense, 2014. 